\title{
Nitrogen-Doped Carbon Nanotube-Supported Pd Catalyst for Improved Electrocatalytic Performance toward Ethanol Electrooxidation
}

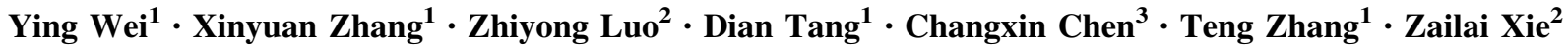

Received: 20 November 2016/ Accepted: 6 January 2017/Published online: 14 February 2017

(C) The Author(s) 2017. This article is published with open access at Springerlink.com

\section{Highlights}

- Hydrothermal carbonization (HTC) enabled the deposition of an N-doped carbon layer on the surface of carbon nanotubes (CNTs).

- Nitrogen-doped CNTs facilitated the uniform distribution of Pd nanoparticles.

- The interaction between nitrogen in the CNTs and Pd favored the existence of metallic Pd in the catalysts.

- $\mathrm{Pd} / \mathrm{HTC}-\mathrm{N} 1.67 \% \mathrm{CNTs}$ showed the highest specific activity toward ethanol oxidation.

\begin{abstract}
In this study, hydrothermal carbonization (HTC) was applied for surface functionalization of carbon nanotubes (CNTs) in the presence of glucose and urea. The HTC process allowed the deposition of thin nitrogen-doped carbon layers on the surface of the CNTs. By controlling the ratio of glucose to urea, nitrogen contents of up to $1.7 \mathrm{wt} \%$ were achieved. The nitrogen-doped carbon nanotube-supported Pd catalysts exhibited superior electrochemical activity for ethanol oxidation relative to the pristine CNTs. Importantly, a 1.5 -fold increase in the specific activity was observed for the Pd/HTC-N1.67\%CNTs relative to the catalyst without nitrogen doping (Pd/HTC-CNTs). Further
\end{abstract}

Teng Zhang

teng_zhang@fzu.edu.cn

$\bowtie$ Zailai Xie

zlxie@fzu.edu.cn

1 College of Materials Science and Engineering, Fuzhou University, Fuzhou 350108, Fujian, People's Republic of China

2 College of Chemistry, Fuzhou University, Fuzhou 350108, Fujian, People's Republic of China

3 Department of Micro/Nano Electronics, School of Electronic Information and Electrical Engineering, Shanghai Jiao Tong University, Shanghai 200240, People's Republic of China experiments indicated that the introduction of nitrogen species on the surface of the CNTs improved the $\operatorname{Pd}(0)$ loading and increased the binding energy.
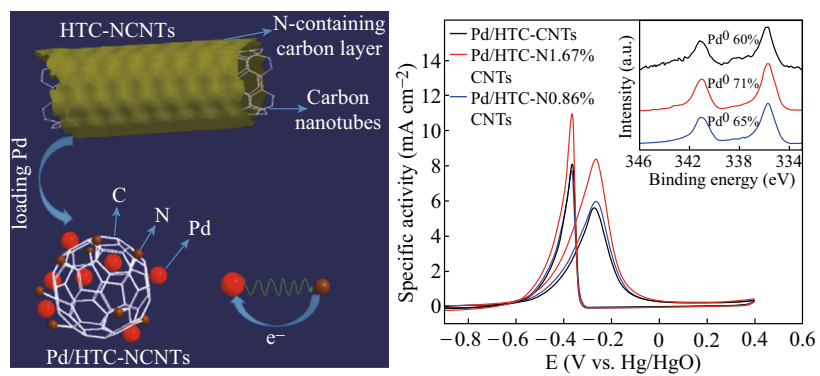

Keywords Direct alcohol fuel cells · Hydrothermal carbonization - Nitrogen-doped carbon nanotubes $\cdot$ Pdbased catalyst $\cdot$ Ethanol electrocatalyst

\section{Introduction}

Direct alcohol fuel cells (DAFCs) have attracted much attention recently due to their high efficiency for energy conversion as well as their low environmental impact 
[1-3]. Among small organic molecules such as methanol, ethanol, and ethylene that yield energy upon oxidation, ethanol is the most ideal fuel because of its abundant reserves, low toxicity, and facile storage and transport. For commercial application, anode catalysts with high activity and stability, such as the widely accepted Pt-based catalysts, are critical for high-performance DAFCs [4, 5]. To address the issues of the high price and low reserves of Ptbased catalysts, many studies have been devoted to developing $\mathrm{Pd}$-based catalysts by regulating the active phases and adding various promoters and varying catalyst supports. For example, certain studies have focused on the addition of secondary elements such as $\mathrm{Sn}, \mathrm{Cu}, \mathrm{Ni}$, and $\mathrm{Au}$ to carbon-supported $\mathrm{Pd}$ to improve the electrocatalytic activity and stability for ethanol oxidation due to the bimetallic synergetic effect [6-8]. Moreover, trimetallic counterparts were also found to exhibit greatly improved catalytic performance and provide greater functionality [9-11].

The support materials also play a significant role in the catalytic reaction. Carbon-based support materials such as active carbon, graphite, and carbon nanotubes (CNTs) have been widely investigated. Among these materials, CNTs have earned distinction based on their high surface area, high length to diameter ratio, and good electrical conductivity $[12,13]$. In addition to the common carbon-class supports, some transition metallic carbides, nitrides, phosphides, and corresponding hybrid composites have been employed as efficient supporting materials that positively impact the catalyst activity [14-16]. Additionally, some studies have shown that doping CNTs with heteroatoms [17-22] is an effective way to tune their intrinsic properties. The substitute heteroatoms can provide more initial nucleation sites for the formation of noble metal nanoparticles and also enhance the interaction with the nanoparticles, thereby improving the electrocatalytic activity [18]. Nitrogen-doped carbon nanotubes (NCNTs) are particularly promising candidates owing to the strong electron donor behavior of nitrogen, which enhances the $\pi$ bonding and the basic properties of the NCNTs [19]. A study by Chetty et al. [20] showed that PtRu nanoparticles supported on nitrogen-doped multiwalled carbon nanotubes exhibited higher activity for methanol oxidation than the same catalysts supported on undoped nanotubes. The introduction of nitrogen-containing functional groups onto a carbon support may improve the catalytic activity by influencing the particle nucleation and growth and changing the electronic structure of the catalyst, as well as increasing the chemical binding energy between the support and catalyst particles, thereby enhancing the durability [21-23].

Furthermore, the use of inexpensive, sustainable feedstocks to produce $\mathrm{N}$-doped carbon materials conforms to the concept of green chemistry. Generally, NCNTs can be synthesized by two methods, i.e., post-doping treatment or direct synthesis $[19,24]$. The post-doping treatment is a multi-step process requiring high-cost apparatus. However, the alternative in situ synthesis requires an expensive precursor, complicated equipment, and is environmentally unfriendly. Therefore, finding a more economic and green strategy to synthesize NCNTs is necessary [25].

The hydrothermal carbonization (HTC) technique is a sustainable approach for producing NCTNs by using inexpensive feedstocks as carbon precursors. Interestingly, Titiricic et al. [26] recently reported that the HTC process enables homogeneous coating of nitrogen-doped carbon layers on the surface of CNTs, leading to superior supercapacitor performance. In spite of the paucity of examples, it is expected that nitrogen functionalization of CNTs by the HTC method could afford interesting supports for anchoring $\mathrm{Pd}$ for heterogeneous reactions.

In this study, surface functionalization of CNTs is performed by the HTC method using glucose and urea. The HTC process allows the deposition of thin nitrogen-doped carbon layers on the surface of the CNTs. By controlling the ratio of glucose to urea, nitrogen contents of up to $1.7 \mathrm{wt} \%$ could be achieved.

\section{Experimental}

The CNTs were functionalized by oxidation with concentrated $\mathrm{HNO}_{3}(70 \%)$ at $110{ }^{\circ} \mathrm{C}$ for $4 \mathrm{~h}$. An appropriate amount of urea, glucose, and pretreated CNTs was mixed and subjected to hydrothermal treatment at $180{ }^{\circ} \mathrm{C}$ for $6 \mathrm{~h}$. After washing and drying, the collected powder was calcined at $900{ }^{\circ} \mathrm{C}$ for $4 \mathrm{~h}$ under Ar atmosphere. The different supporting materials, i.e., without N-doping (HTC-CNTs), doped with $0.86 \% \mathrm{~N}$ (HTC-N0.86\%CNTs) and $1.67 \% \mathrm{~N}$ (HTC-N1.67\%CNTs), were obtained by similar procedures. Elemental analysis was performed by using an elemental analyzer (Vario EL Cube). The elemental analysis results for the different supporting materials are summarized in Table 1.

The Pd-based catalyst was synthesized using $\mathrm{PdCl}_{2}$ as the metal source, $\mathrm{NaBH}_{4}$ as the reducing agent, and the different composites as supporting materials. Thus, $48 \mathrm{mg}$

Table 1 Elemental analysis data for supporting materials

\begin{tabular}{lllll}
\hline Supporting materials & \multicolumn{5}{l}{ Elemental compositions (wt\%) } \\
\cline { 2 - 5 } & $\mathrm{N}$ & $\mathrm{C}$ & $\mathrm{H}$ & $\mathrm{O}$ \\
\hline HTC-CNT & 0 & 90.28 & 2.60 & 6.12 \\
HTC-N1.67\%CNT & 1.67 & 88.60 & 2.64 & 6.09 \\
HTC-N0.86\%CNT & 0.86 & 89.29 & 2.66 & 6.19 \\
\hline
\end{tabular}


of the pretreated HTC-CNTs and $1.3 \mathrm{~mL}$ of $18.9 \mathrm{mM} \mathrm{H}_{2}$ $\mathrm{PdCl}_{4}$ were mixed with $30 \mathrm{~mL}$ of deionized water under ultrasonic stirring. The $\mathrm{pH}$ of the solution was adjusted to 9 by using $1 \mathrm{M} \mathrm{NaOH}$. An appropriate amount of $\mathrm{NaBH}_{4}$ $\left(\mathrm{Pd} / \mathrm{NaBH}_{4}=1: 8 \mathrm{~mol} \%\right)$ was then added dropwise to the aforementioned solution (with a nominal Pd loading of $5 \mathrm{wt} \%$ ), and the mixture was stirred vigorously for $4 \mathrm{~h}$. The resulting precipitate was filtered and washed several times with ultrapure water before drying overnight at $60{ }^{\circ} \mathrm{C}$. The weight percentage of $\mathrm{Pd}$ in the catalysts, determined by inductively coupled plasma-atomic emission spectroscopy (ICP-AES), was $4.9 \pm 0.1 \mathrm{wt} \%$.

$\mathrm{X}$-ray diffraction (XRD, Rigaku D/max-IIIC) was performed using a copper $K \alpha$ source $(\lambda=1.5406 \AA)$. The microstructure was analyzed using high-resolution transmission electron microscopy (HRTEM, Tecnai G2 F20 S-TWIN) at $200 \mathrm{kV}$. X-ray photoelectron spectroscopy (XPS, ESCALAB 250, Thermo Scientific, Inc.) was performed using a monochromatic $\mathrm{Al} K \alpha$ source at $10 \mathrm{~mA}$ and $15 \mathrm{kV}$. The electrochemical measurements were conducted by using a CHI660D electrochemical workstation (Chenhua Inc., Shanghai, China) in a conventional, sealed, threeelectrode system. Raman spectra were collected between 500 and $3100 \mathrm{~cm}^{-1}$. The light source was a $532 \mathrm{~nm}$ argon laser, and the data were collected with 50-s exposure.

A Pt wire and a $\mathrm{Hg} / \mathrm{HgO}$ electrode were used as the counter electrode and reference electrode, respectively. A glassy carbon electrode (GCE, $\varnothing 3 \mathrm{~mm}$ ) was employed as the working electrode; the working electrode was prepared as follows: $5 \mathrm{mg}$ of the catalyst was ultrasonically mixed with $25 \mu \mathrm{L}$ of $20 \mathrm{wt} \%$ Nafion solution and $975 \mu \mathrm{L}$ of isopropyl alcohol to prepare a homogeneous catalyst ink. A $4 \mu \mathrm{L}$ portion of the catalyst ink was transferred onto the polished glassy carbon electrode surface using a micropipette. The Pd loading on the surface of the glassy carbon electrode surface was $0.014 \mathrm{mg} \mathrm{cm}^{-2}$. Cyclic voltammograms were acquired in the potential range of -0.9 to $0.4 \mathrm{~V}$ with a sweep rate of $50 \mathrm{mV} \mathrm{s}^{-1}$, in $1 \mathrm{M} \mathrm{KOH}$ and $1 \mathrm{M} \mathrm{KOH}$ containing $1 \mathrm{M}$ ethanol, respectively. Chronoamperometry was carried out at a potential of $-0.3 \mathrm{~V}$ using $1 \mathrm{M} \mathrm{KOH}$ solution containing $1 \mathrm{M}$ ethanol.

For the electrochemical CO-stripping measurements, $\mathrm{CO}$ was bubbled into the solution of $1 \mathrm{M} \mathrm{KOH}$ for $15 \mathrm{~min}$ after deoxygenation of the solution. $\mathrm{N}_{2}(99.9 \%)$ was then bubbled into the solution for $20 \mathrm{~min}$ to remove CO. During the process of ethanol electrooxidation in alkaline media in the presence of adequate $\mathrm{OH}^{-}$, the oxidation mechanism associated with $\mathrm{CO}_{\text {ads }}$ can be summarized as follows,

$\mathrm{Pd}-\mathrm{CO}_{\mathrm{ads}}+2 \mathrm{OH}^{-} \rightarrow \mathrm{M}+\mathrm{CO}_{2}+\mathrm{H}_{2} \mathrm{O}+2 \mathrm{e}^{-}$

All solutions were deoxygenated by bubbling with $\mathrm{N}_{2}$ before the tests, and all electrochemical measurements were carried out in a water bath at $25 \pm 1{ }^{\circ} \mathrm{C}$.

\section{Results and Discussion}

The surface state of the three as-prepared catalysts was investigated by measuring the stable cyclic voltammograms in $1 \mathrm{M} \mathrm{KOH}$ solution (Fig. 1); the typical $\mathrm{OH}^{-}$ adsorption peak was observed in the scan from -0.6 to $-0.4 \mathrm{~V}$, and the reduction peak of $\mathrm{PdO}$ was observed in the reverse scan from -0.4 to $0 \mathrm{~V}[27,28]$. From comparison of these three catalysts, it is notable that the current density of the $\mathrm{OH}^{-}$adsorption peak of the Pd/HTC-N1.67\%CNTs was higher than that of Pd/HTC-CNT, where the current density of the former is useful for the removal of CO-like intermediates. More significantly, in the reverse scan, the reduction peak for the oxygenated species of the Pd/HTC$\mathrm{N} 1.67 \% \mathrm{CNTs}$ occurred at much higher potential than that of the Pd/HTC-CNTs. The peak for the Pd/HTC$\mathrm{N} 1.67 \% \mathrm{CNTs}$ also occurred at a lower potential, which is beneficial for ethanol oxidation.

Figure 2 shows the cyclic voltammograms for the three catalysts in $1 \mathrm{M} \mathrm{KOH}$ containing $1 \mathrm{M}$ ethanol. The anodic peak observed in the forward scan corresponds to ethanol oxidation, which is of great significance for evaluating the activity of the catalysts [29]. The current density of the forward anodic peak of the Pd/HTC-N1.67\%CNTs $\left(2988 \mathrm{~mA} \mathrm{mg}^{-1}\right)$ was higher than that of the Pd/HTCN0.86\%CNTs $\left(2052 \mathrm{~mA} \mathrm{mg}^{-1}\right)$ and the Pd/HTC-CNTs $\left(1718 \mathrm{~mA} \mathrm{mg}^{-1}\right)$. This implies that the NCNT-supported Pd catalysts have higher catalytic activity for ethanol electrooxidation.

It is known that during the ethanol oxidation process, some reaction intermediates like $\mathrm{CO}$ will be strongly adsorbed on the Pd surface, resulting in poisoning of the catalyst. A CO-stripping test was conducted to evaluate the capability of the catalysts for the removal of adsorbed CO-

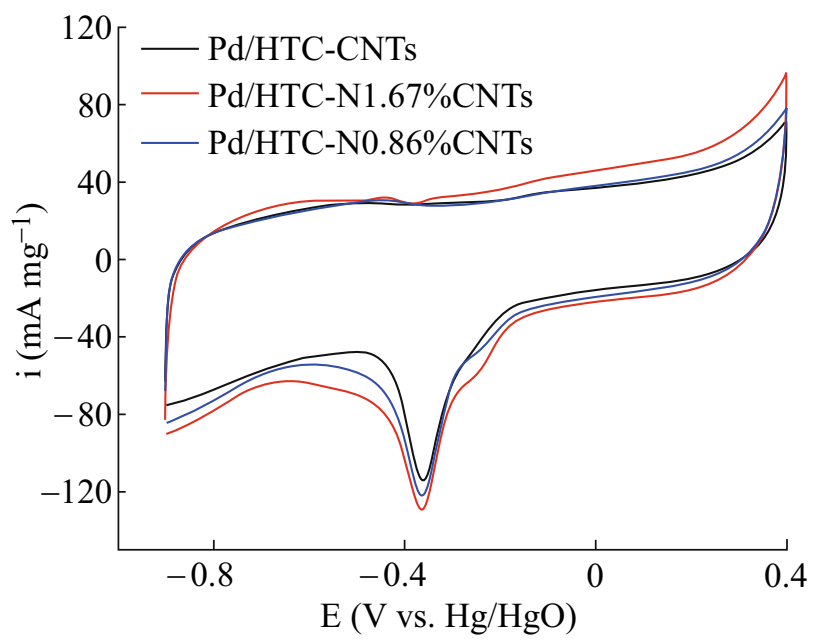

Fig. 1 Cyclic voltammograms for different catalysts in $1 \mathrm{M} \mathrm{KOH}$ solution 


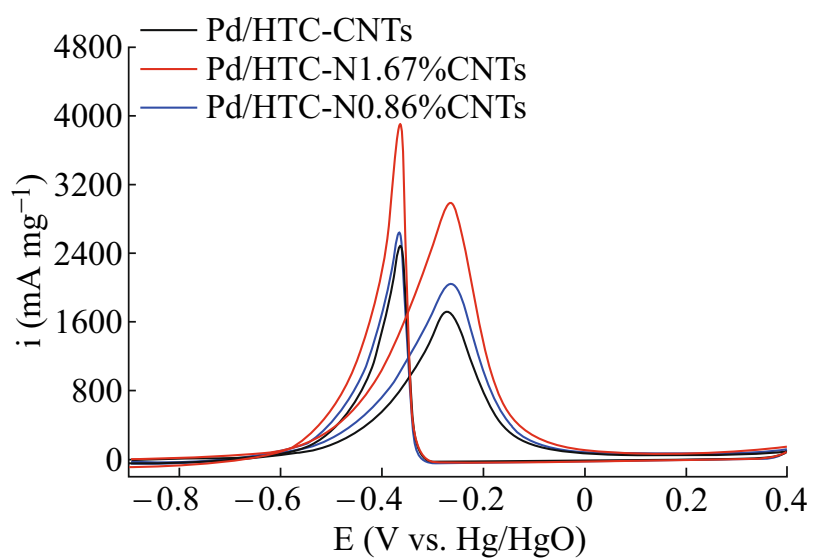

Fig. 2 Cyclic voltammograms for different catalysts in $1 \mathrm{M} \mathrm{KOH}$ solution containing $1 \mathrm{M}$ ethanol

like species. The CO-stripping curves of the three catalysts in $1 \mathrm{M} \mathrm{KOH}$ solution are shown in Fig. 3a-c. The electrochemically active surface area (EAS) can be estimated from the CO-stripping measurements. Typically, the COstripping curve can be determined by the electrochemical oxidation of pre-adsorbed saturated $\mathrm{CO}_{\mathrm{ads}}$. The specific EAS of the catalyst can be calculated based on the following equation $[30,31]$,

$\mathrm{EAS}=Q / m C$

$Q=0.02 \mathrm{~S} / \mathrm{m}$ where $Q$ is the charge for CO desorption-electrooxidation, $m$ is the Pd loading, and $C\left(420 \mu \mathrm{C} \mathrm{cm}^{-2}\right)$ indicates the conversion factor. The detailed calculation process is provided as follows:

According to Fig. 3a-c, the integral area $(S)$ of Pd/HTCCNTs, Pd/HTC-N1.67\%CNTs, Pd/HTC-N0.86\%CNTs are 6.43, 5.54, $7.17 \mathrm{~mA} \mathrm{mg}^{-1} \mathrm{~V}$, respectively. Based on Eq. 3, $Q$ of Pd/HTC-CNTs, Pd/HTC-N1.67\%CNTs, Pd/HTCN0.86\%CNTs are $12.86 \times 10^{-5}, \quad 11.08 \times 10^{-5}$ and $14.34 \times 10^{-5} \mathrm{C}$, respectively. Based on Eq. 2, the EAS of Pd/HTC-CNTs, Pd/HTC-N1.67\%CNTs, Pd/HTC$\mathrm{N} 0.86 \% \mathrm{CNTs}$ is $30.6,36.0,34.2 \mathrm{~m}^{2} \mathrm{~g}^{-1}$, respectively. Finally, the calculated EAS values for the Pd/HTC-CNTs, Pd/HTC-N1.67\%CNTs, and Pd/HTC-N0.86\%CNTs were $30.6,36.0$, and $34.2 \mathrm{~m}^{2} \mathrm{~g}^{-1}$, respectively.

The cyclic voltammograms of the three catalysts were acquired in $1 \mathrm{M} \mathrm{KOH}$ containing $1 \mathrm{M}$ ethanol (Fig. 2); the current normalized relative to the EAS is shown in Fig. 3d. The specific activity is often used to represent the intrinsic performance of catalysts. The anodic peak observed in the forward scan corresponds to ethanol oxidation, which is of great significance for evaluating the activity of the catalysts. It is clear that the forward anodic peak current density of the Pd/HTC-N1.67\%CNTs $\left(8.3 \mathrm{~mA} \mathrm{~cm}^{-2}\right)$ is higher than that of the Pd/HTC-N0.86\%CNTs $\left(6.0 \mathrm{~mA} \mathrm{~cm}^{-2}\right)$ and $\mathrm{Pd} / \mathrm{HTC}-\mathrm{CNTs}\left(5.6 \mathrm{~mA} \mathrm{~cm}^{-2}\right)$. Chen et al. [32] reported that the specific activities of $\mathrm{Pd} / \mathrm{C}$ and $\mathrm{Pd} / 50 \mathrm{CaSiO}_{3} / \mathrm{C}$ were
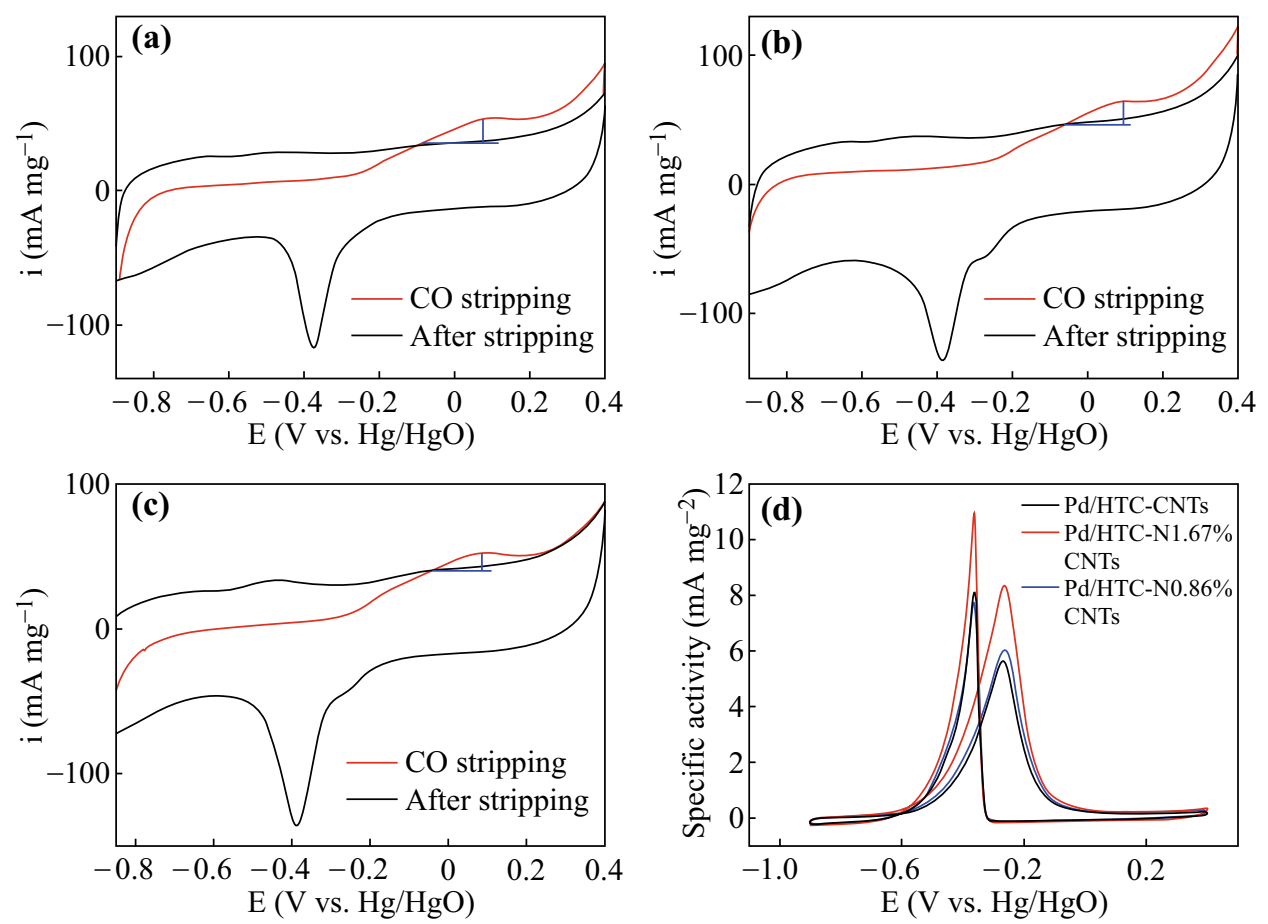

Fig. 3 CO-stripping voltammograms for a Pd/HTC-CNTs, b Pd/HTC-N1.67\%CNTs, and c Pd/HTC-N0.86\%CNTs in $1 \mathrm{M}$ KOH solution, d cyclic voltammograms of different catalysts in $1 \mathrm{M} \mathrm{KOH}$ containing $1 \mathrm{M}$ ethanol (in Fig. 2), normalized by EAS 

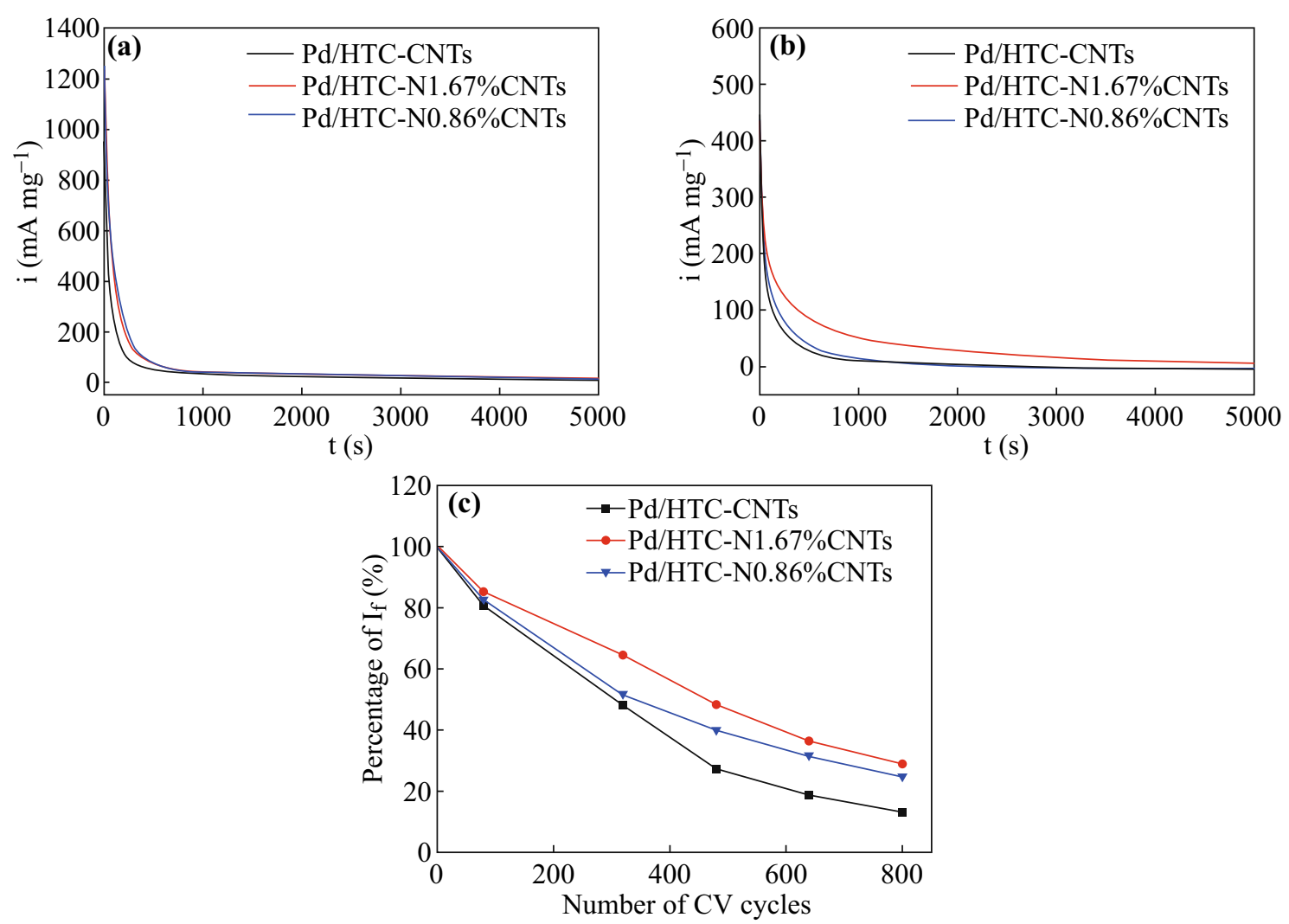

Fig. 4 a Chronoamperometric curves for different catalysts, recorded at $-0.3 \mathrm{~V}$ in $1 \mathrm{M} \mathrm{KOH}$ solution containing $1 \mathrm{M}$ ethanol, b chronoamperometric curves for different catalysts, recorded at $-0.25 \mathrm{~V}$ in $1 \mathrm{M} \mathrm{KOH}$ solution containing $1 \mathrm{M}$ methanol, c peak current densities for different catalysts, recorded in $1 \mathrm{M} \mathrm{KOH}$ solution containing $1 \mathrm{M}$ ethanol, as a function of the cycle number

2.7 and $4.4 \mathrm{~mA} \mathrm{~cm}^{-2}$, respectively. Therefore, the specific activity of the Pd/HTC-N1.67\%CNTs catalyst in the present work is about three times higher than that of Pd-based catalysts in the literature.

To evaluate the stability of the catalysts, chronoamperometry curves were collected at the potential of $-0.3 \mathrm{~V}$ in $1 \mathrm{M} \mathrm{KOH}$ containing $1 \mathrm{M}$ ethanol (Fig. 4a). The Pd/HTC$\mathrm{N} 1.67 \% \mathrm{CNTs}$ catalyst displayed the highest initial anodic oxidation current density due to its high electrocatalytic activity for ethanol oxidation, which corresponds to the activity results. Moreover, because of the formation of COlike intermediates, the current densities of all the catalysts exhibited a rapid decline and reached a pseudo-steady state $[33,34]$. Compared to the Pd/HTC-CNTs catalyst, the Pd/ HTC-N1.67\%CNTs catalyst exhibited a higher steady state current density with slower decay throughout the process of ethanol oxidation. However, to eliminate the influence of $\mathrm{CH}_{3} \mathrm{COO}^{-}$during ethanol electrooxidation, as shown in Fig. $4 \mathrm{~b}$, another set of chronoamperometry curves were collected using $1 \mathrm{M} \mathrm{KOH}$ containing $1 \mathrm{M}$ methanol, where $\mathrm{CH}_{3} \mathrm{COO}_{\text {ads }}^{-}$cannot be produced [28, 30]. From the evaluation of the performance of the catalysts toward methanol electrooxidation, it is verified that the $\mathrm{Pd} / \mathrm{HTC}$ N1.67\%CNTs catalyst exhibits higher stability for the

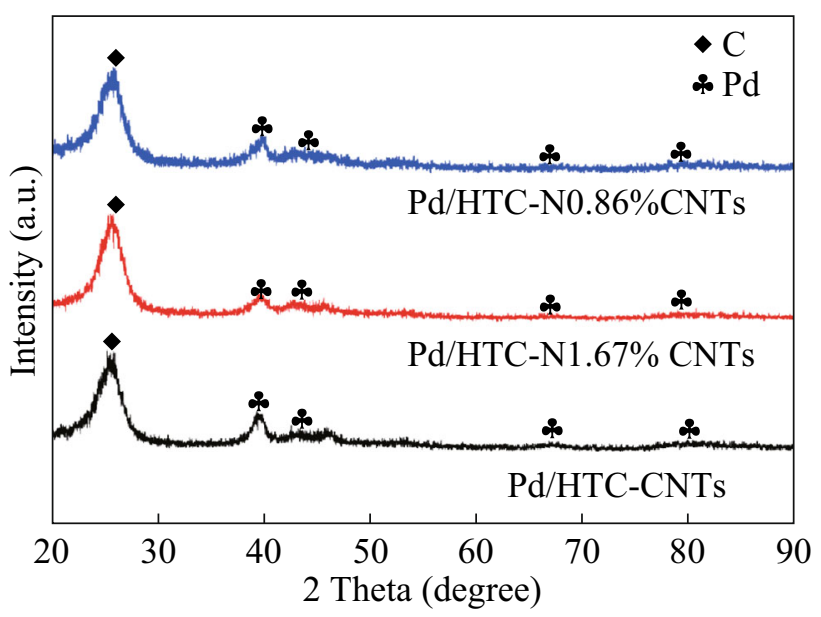

Fig. 5 XRD patterns of different catalysts

corresponding electrooxidation of ethanol. However, for comparison with the chronoamperometry curves, a more convincing and accurate test was carried out as shown in Fig. 4c. The cyclic voltammograms of all the catalysts were also measured in $1 \mathrm{M} \mathrm{KOH}$ solution containing $1 \mathrm{M}$ ethanol for 800 cycles. After normalizing the peak current density of the catalysts as a function of the cycle numbers, it was 

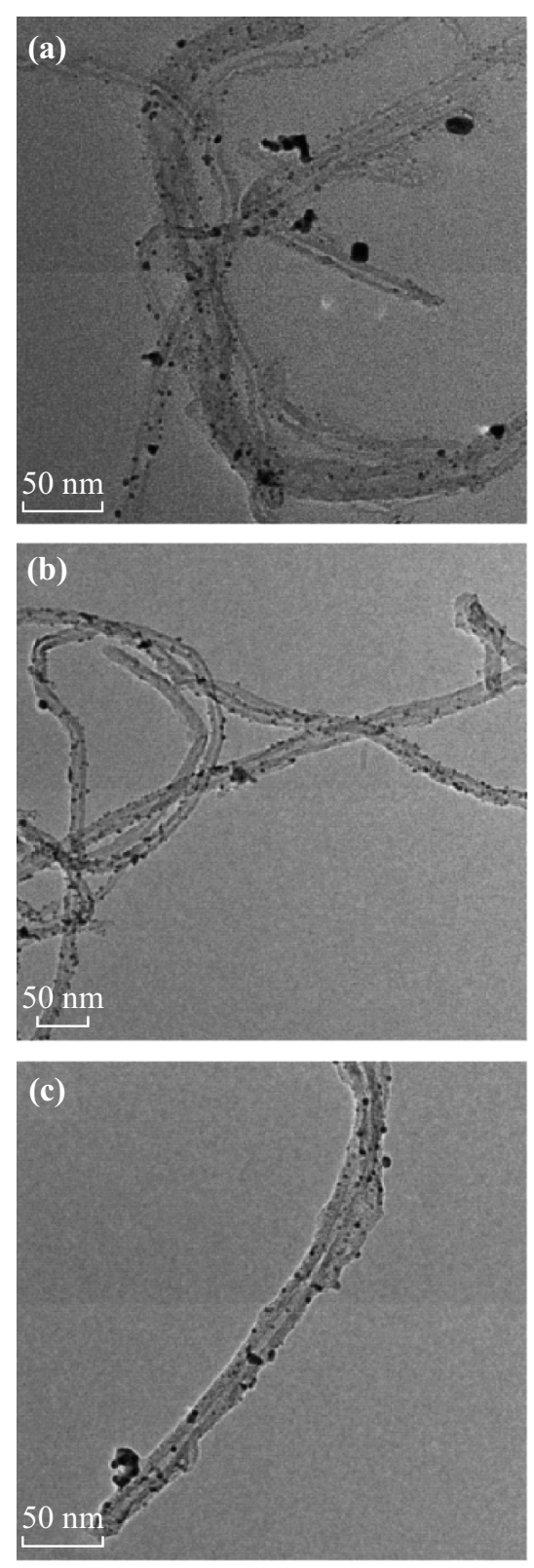
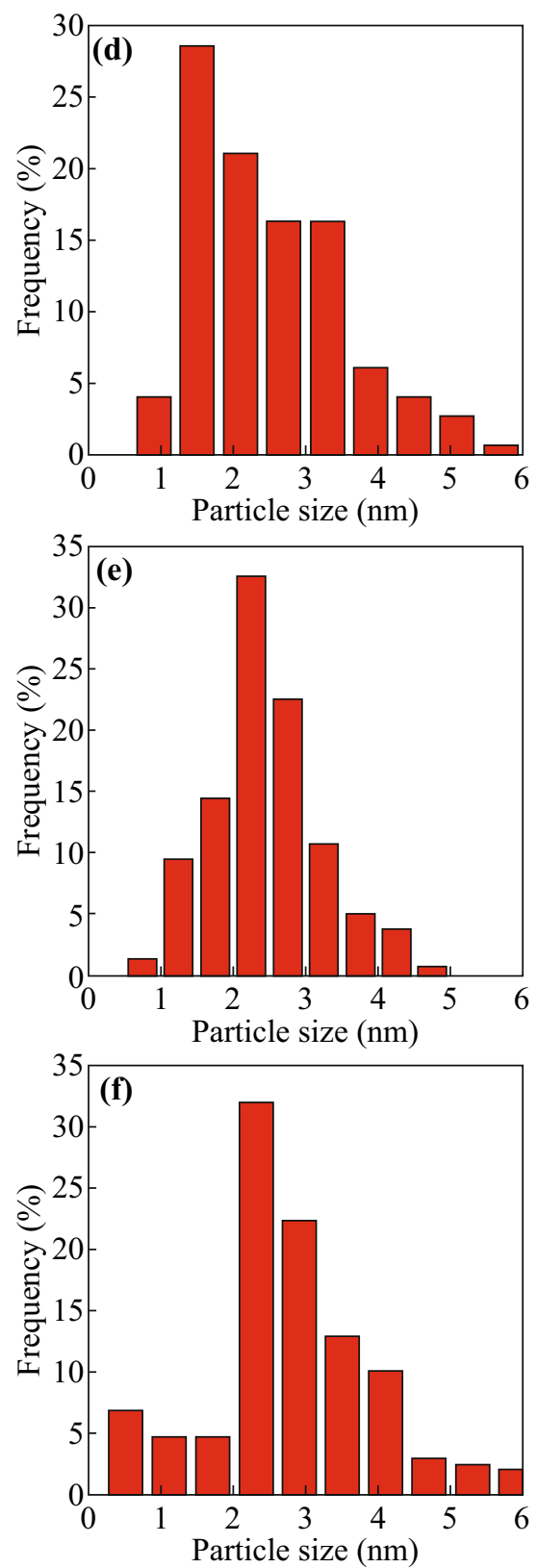
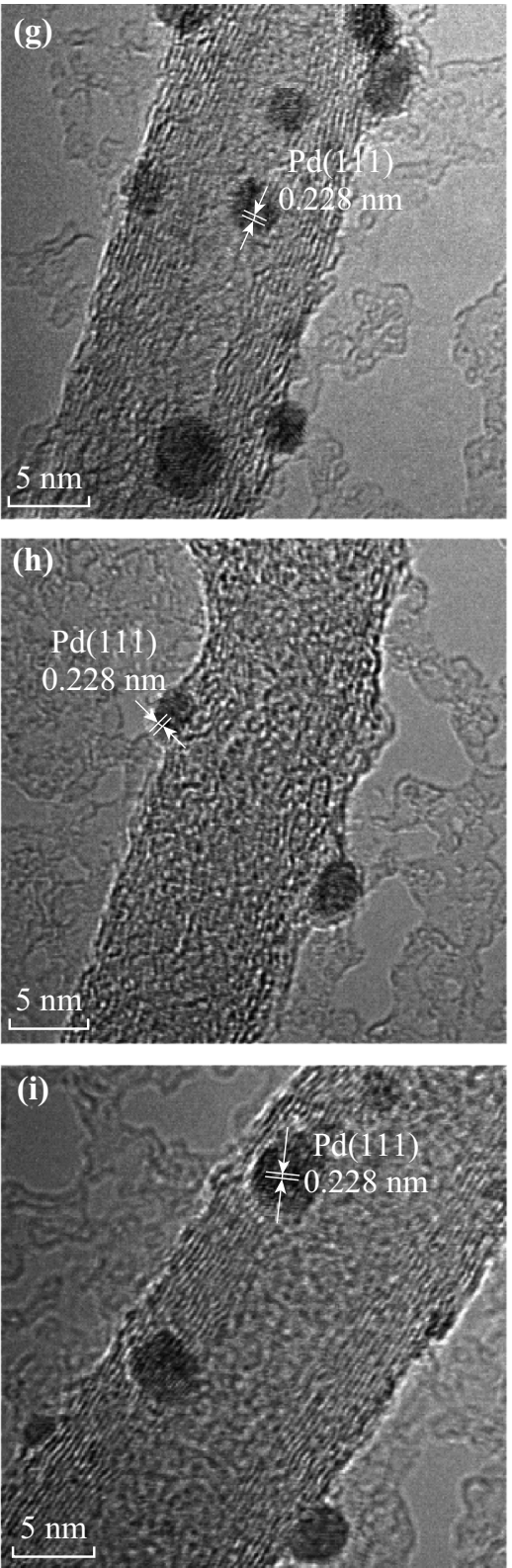

Fig. 6 TEM images of a Pd/HTC-CNTs, b Pd/HTC-N1.67\%CNTs, $\mathbf{c}$ Pd/HTC-N0.86\%CNTs; $\mathbf{d}-\mathbf{f}$ are the size distribution images for a-c, respectively. HRTEM images of $\mathbf{g}$ Pd/HTC-CNTs, h Pd/HTC-N1.67\%CNTs, i Pd/HTC-N0.86\%CNTs

clear that the Pd/HTC-N1.67\%CNTs exhibited the highest peak current density for the process of ethanol oxidation. The remaining fraction of the peak current density increased from $13 \%$ for the Pd/HTC-CNTs to $24.8 \%$ for the Pd/HTCN0.86\%CNTs, and to $29 \%$ for the Pd/HTC-N1.67\%CNTs after 800 cycles. Thus, the Pd/HTC-N1.67\%CNTs catalyst demonstrated the best stability for ethanol oxidation, which is consistent with the chronoamperometry and CO-stripping voltammogram measurements.
Figure 5 shows the XRD patterns of the Pd/HTC-CNTs, $\mathrm{Pd} / \mathrm{HTC}-\mathrm{N} 1.67 \% \mathrm{CNTs}$, and Pd/HTC-N0.86\%CNTs samples. The diffraction patterns exhibit several peaks at $39.9^{\circ}$ (111), $46.1^{\circ}(200)$, and $67.5^{\circ}$ (220), suggesting the formation of Pd nanoparticles. There was also a small amount of palladium oxide. In addition, the full-widths-at-halfmaximum of these three catalysts were very close, which implies that the particle size of Pd was similar for all the catalysts. 
Figure 6a-c, g-i shows the typical TEM and HRTEM images of the synthesized catalysts, respectively. It is clear that the Pd nanoparticles were uniform and monodisperse on all three surfaces. In addition, the average particle size of the Pd nanoparticles was about $2.5 \mathrm{~nm}$ for all the catalysts (Fig. 6d-f).

The XRD and TEM data exclude the effects of the particle size and the dispersion of the Pd nanoparticles. Therefore, XPS measurements were conducted as shown in Fig. 7. The XPS Pd 3d spectra for the three catalysts (Fig. 7a) show peaks corresponding to $\mathrm{Pd} 3 \mathrm{~d}_{5 / 2}$ $(\sim 335.7 \mathrm{eV})$ and $\mathrm{Pd} 3 \mathrm{~d}_{3 / 2}(\sim 341.0 \mathrm{eV})$ that can be ascribed to $\mathrm{Pd}$ and $\mathrm{PdO}_{y}(0<y<2)$ species, respectively $[34,35]$. The respective $\mathrm{Pd} / \mathrm{PdO}_{y}$ ratios were $1.5,1.9$, and 2.5 for the Pd/HTC-CNTs, Pd/HTC-N0.86\%CNTs, and Pd/ HTC-N1.67\%CNTs. It is known that metallic Pd accounts for the electrocatalytic active sites in the catalyst and produces superior catalytic activity $[22,36]$. Therefore, the
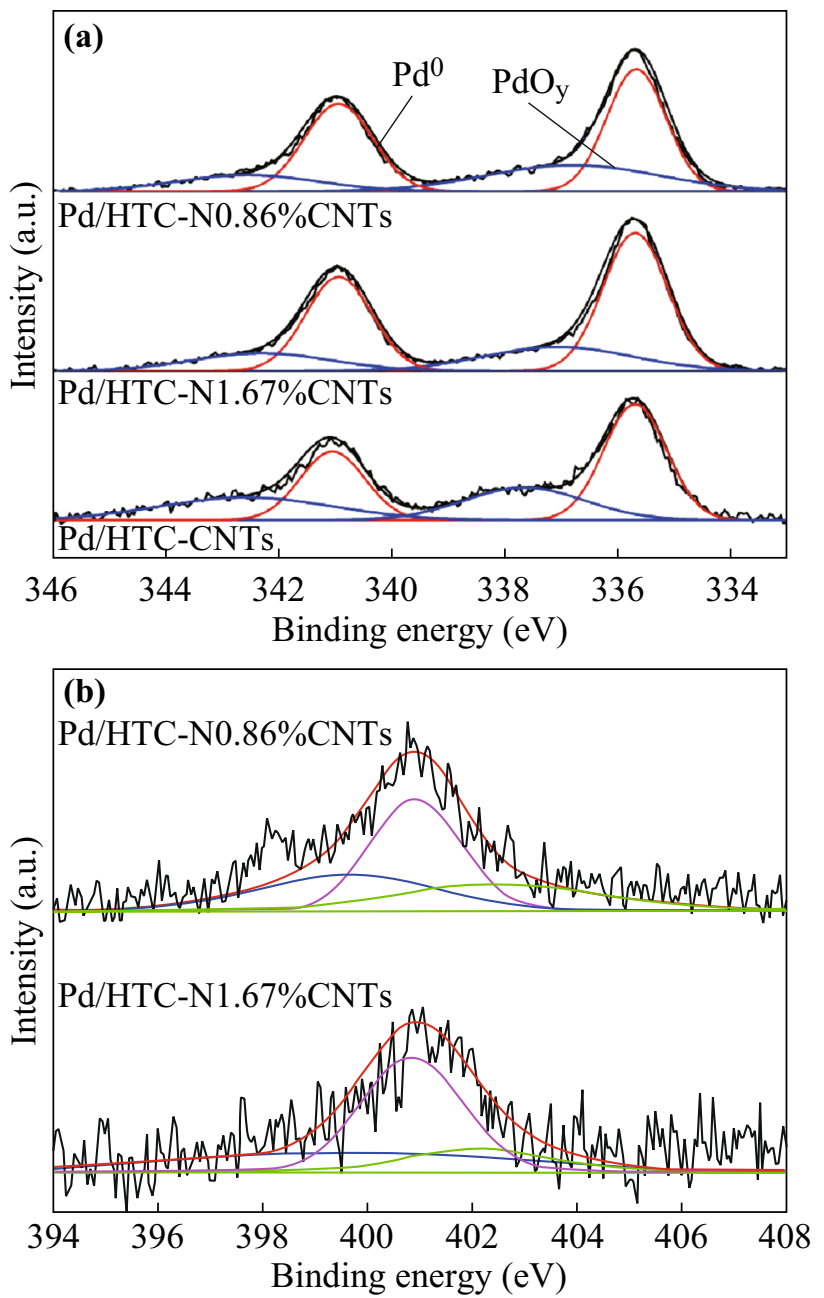

Fig. 7 a XPS spectra of Pd/HTC-N0.86\%CNTs, Pd/HTC$\mathrm{N} 1.67 \% \mathrm{CNTs}$, and $\mathrm{Pd} / \mathrm{HTC}-\mathrm{CNTs}$ in $\mathrm{Pd} 3 \mathrm{~d}$ region, and b $\mathrm{N} 1 \mathrm{~s}$ spectra of Pd/HTC-N0.86\%CNTs and Pd/HTC-N1.67\%CNTs highest fraction of metallic $\mathrm{Pd}$ in the $\mathrm{Pd} / \mathrm{HTC}$ $\mathrm{N} 1.67 \% \mathrm{CNTs}$ is consistent with its best electrochemical performance achieved with this system.

The $\mathrm{Pd} 3 \mathrm{~d}_{5 / 2}$ peak was also negatively shifted for the $\mathrm{Pd} /$ HTC-N1.67\%CNTs catalyst $(340.95 \mathrm{eV})$ relative to that of the Pd/HTC-CNTs (341.05 eV) catalyst. Moreover, Fig. 7b shows a positive shift of the N1s binding energy from $400.75 \mathrm{eV}$ for the Pd/HTC-N0.86\%CNTs to $401 \mathrm{eV}$ for the Pd/HTC-N1.67\%CNTs. This confirms the interaction between Pd and N [37-39]. Therefore, due to the electrondonating effects of nitrogen, the electron cloud density of Pd may increase, which can stabilize $\mathrm{Pd}^{0}$, and the nitrogen groups impart a basic nature to the carbon surface and bind strongly to Pd, enhancing the Pd dispersion and preventing agglomeration of the $\mathrm{Pd}$ particles, thereby improving the electrochemical activity and stability of the Pd-based catalysts $[21,25,34]$. Accordingly, the Pd/HTC-

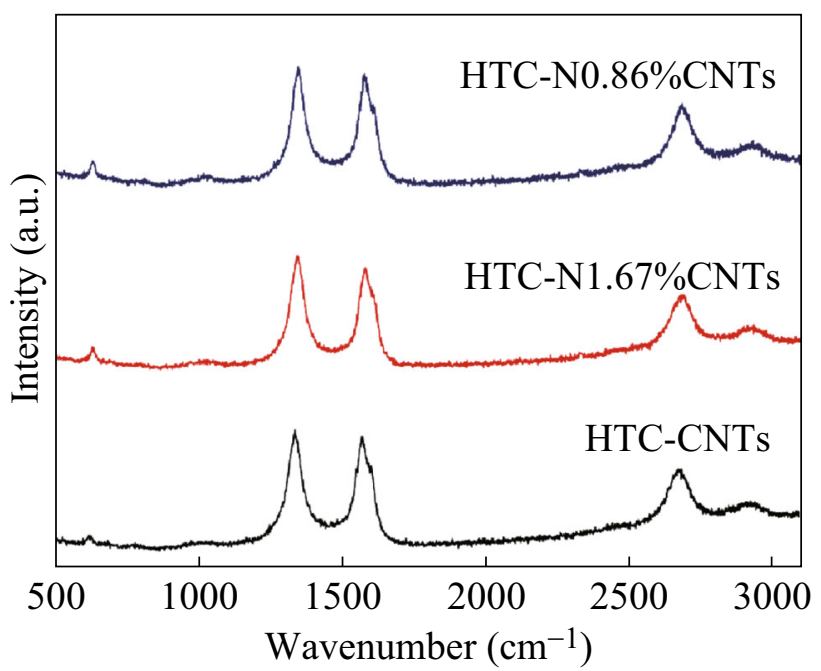

Fig. 8 Raman spectra of HTC-N0.86\%CNTs, HTC-N1.67\%CNTs, and HTC-CNTs supports

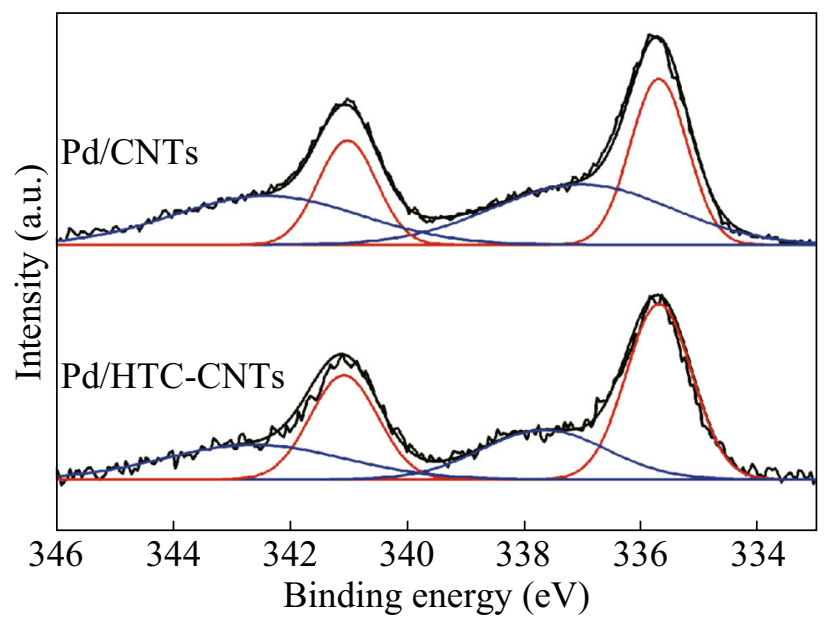

Fig. 9 XPS spectra of Pd/CNTs and Pd/HTC-CNTs in Pd 3d region 
N1.67\%CNTs catalyst showed the best activity and stability toward ethanol electrooxidation.

The Raman spectra presented in Fig. 8 show the degree of graphitization of the CNTs. The profiles of all samples displayed three characteristic peaks at $\sim 1343, \sim 1569$, and $\sim 2690 \mathrm{~cm}^{-1}$, assigned to the vibration of carbon atoms with dangling bonds and first-order scattering of the E2g phonons of the $s p^{2}$ carbon atoms, respectively. Narrow D and $\mathrm{G}$ bands accompanied by a strong $2 \mathrm{D}$ band indicate ordering of the graphite structure. Furthermore, the intensity ratio $\left(I_{D} / I_{G}\right)$ of the three CNTs followed the order: 1.049(HTC-N1.67\%CNTs) $<1.054$ (HTC-

N0.8\%CNTs) $<1.087$ (HTC-CNTs), indicating the presence of amorphous carbon layers with a number of defects after the HTC process. The defects on the surface of the NCNTs also help to anchor metallic $\mathrm{Pd}$ for ethanol electrooxidation.

The valence of $\mathrm{Pd}$ in the Pd/HTC-CNTs and Pd/CNTs catalysts was also determined by XPS analysis, as shown in Fig. 9. The $\mathrm{Pd} / \mathrm{PdO}_{y}$ ratio was calculated to be 0.8 and 1.5 for the $\mathrm{Pd} / \mathrm{CNT}$ s and $\mathrm{Pd} / \mathrm{HTC}-\mathrm{CNTs}$, respectively. The results indicate that the defects introduced by the HTC process help to anchor metallic Pd for ethanol electrooxidation, which is beneficial for enhancing the catalyst performance.

\section{Conclusions}

Three Pd-based catalysts supported on NCNTs with various nitrogen contents were synthesized via the HTC process. The Pd/HTC-N1.67\%CNTs catalyst exhibited the best ethanol electrooxidation activity and stability as well as the highest specific activity. This improvement can be attributed to the interaction between nitrogen (doped in the CNTs) and the Pd nanoparticles, which favors the formation of metallic $\mathrm{Pd}$ in the catalysts. The HTC process also supplies a number of defects on the surface of the NCNTs that help to anchor metallic Pd for ethanol electrooxidation. The large proportion of metallic $\mathrm{Pd}$ not only facilitates $\mathrm{OH}^{-}$adsorption and the removal of the CO-like intermediates, but also increases the specific activity of the catalyst, resulting in a significant improvement of the activity and stability of the Pd-containing catalysts.

Acknowledgements The authors gratefully acknowledge the financial support of the National Natural Science Foundation of China (Nos. 51672045 and 11374053), and Key Program of Universityindustry Collaboration from Science and Technology Department of Fujian Province (No. 2015H6009). They would also like to thank Xinqi Zhang for assistance with TEM and Zhenhuan Zheng for assistance with X-ray diffraction analysis.
Open Access This article is distributed under the terms of the Creative Commons Attribution 4.0 International License (http://crea tivecommons.org/licenses/by/4.0/), which permits unrestricted use, distribution, and reproduction in any medium, provided you give appropriate credit to the original author(s) and the source, provide a link to the Creative Commons license, and indicate if changes were made.

\section{References}

1. C. Lamy, A. Lima, V. LeRhun, F. Delime, C. Coutanceau, J.-M. Léger, Recent advances in the development of direct alcohol fuel cells (DAFC). J. Power Sources 105(2), 283-296 (2002). doi:10. 1016/S0378-7753(01)00954-5

2. Z. Zhang, C. Zhang, J. Sun, T. Kou, Q. Bai, Y. Wang, Y. Ding, Ultrafine nanoporous $\mathrm{PdFe} / \mathrm{Fe}_{3} \mathrm{O}_{4}$ catalysts with doubly enhanced activities towards electro-oxidation of methanol and ethanol in alkaline media. J. Mater. Chem. 1(11), 3620-3628 (2013). doi:10. 1039/c3ta01464a

3. M.K. Debe, Electrocatalyst approaches and challenges for automotive fuel cells. Nature 486(7401), 43-51 (2012). doi:10.1038/ nature 11115

4. L. Yu, J. Xi, $\mathrm{CeO}_{2}$ nanoparticles improved Pt-based catalysts for direct alcohol fuel cells. Int. J. Hydrogen Energy 37(21), 15938-15947 (2012). doi:10.1016/j.ijhydene.2012.08.063

5. Y.H. Chu, Y.G. Shul, Combinatorial investigation of Pt-Ru-Sn alloys as an anode electrocatalysts for direct alcohol fuel cells. Int. J. Hydrogen Energy 35(20), 11261-11270 (2010). doi:10. 1016/j.ijhydene.2010.07.062

6. Y. Zhou, C. Liu, J. Liu, X. Cai, Y. Lu, H. Zhang, X. Sun, S. Wang, Self-decoration of PtNi alloy nanoparticles on multiwalled carbon nanotubes for highly efficient methanol electrooxidation. Nano-Micro Lett. 8(4), 371-380 (2016). doi:10.1007/ s40820-016-0096-2

7. C.W. Xu, H. Wang, P.K. Shen, S.P. Jiang, Highly ordered pd nanowire arrays as effective electrocatalysts for ethanol oxidation in direct alcohol fuel cells. Adv. Mater. 19(23), 4256-4259 (2007). doi:10.1002/adma.200602911

8. T. Maiyalagan, K. Scott, Performance of carbon nanofiber supported $\mathrm{Pd}-\mathrm{Ni}$ catalysts for electro-oxidation of ethanol in alkaline medium. J. Power Sources 195(16), 5246-5251 (2010). doi:10. 1016/j.jpowsour.2010.03.022

9. F. Zhu, M. Wang, Y. He, G. Ma, Z. Zhang, X. Wang, A comparative study of elemental additives ( $\mathrm{Ni}$, Co and $\mathrm{Ag}$ ) on electrocatalytic activity improvement of PdSn-based catalysts for ethanol and formic acid electro-oxidation. Electrochim. Acta 148, 291-301 (2014). doi:10.1016/j.electacta.2014.10.062

10. X. Wang, F. Zhu, Y. He, M. Wang, Z. Zhang, Z. Ma, R. Li, Highly active carbon supported ternary PdSnPtx $(x=0.1-0.7)$ catalysts for ethanol electro-oxidation in alkaline and acid media. J. Colloid Interface Sci. 468, 200-210 (2016). doi:10.1016/j.jcis. 2016.01.068

11. X. Wang, G. Ma, F. Zhu, N. Lin, B. Tang, Z. Zhang, Preparation and characterization of micro-arc-induced $\mathrm{Pd} / \mathrm{TM}(\mathrm{TM}=\mathrm{Ni}, \mathrm{Co}$ and $\mathrm{Ti}$ ) catalysts and comparison of their electrocatalytic activities toward ethanol oxidation. Electrochim. Acta 114, 500-508 (2013). doi:10.1016/j.electacta.2013.10.049

12. B. Yoon, C.M. Wai, Microemulsion-templated synthesis of carbon nanotube-supported pd and rh nanoparticles for catalytic applications. J. Am. Chem. Soc. 127(49), 17174-17175 (2005). doi:10.1021/ja055530f

13. O. Winjobi, Z. Zhang, C. Liang, W. Li, Carbon nanotube supported platinum-palladium nanoparticles for formic acid 
oxidation. Electrochim. Acta 55(13), 4217-4221 (2010). doi:10. 1016/j.electacta.2010.02.062

14. F. Hu, G. Cui, Z. Wei, P.K. Shen, Improved kinetics of ethanol oxidation on Pd catalysts supported on tungsten carbides/carbon nanotubes. Electrochem. Commun. 10(9), 1303-1306 (2008). doi:10.1016/j.elecom.2008.06.019

15. M.M.O. Thotiyl, T.R. Kumar, S. Sampath, Pd supported on titanium nitride for efficient ethanol oxidation. J. Phys. Chem. C 114(41), 17934-17941 (2010). doi:10.1021/jp1038514

16. R. Li, Z. Ma, F. Zhang, H. Meng, M. Wang, X.-Q. Bao, B. Tang, $\mathrm{X}$. Wang, Facile Cu3P-C hybrid supported strategy to improve Pt nanoparticle electrocatalytic performance toward methanol, ethanol, glycol and formic acid electro-oxidation. Electrochim. Acta 220, 193-204 (2016). doi:10.1016/j.electacta.2016.10.105

17. Y. Yan, J. Miao, Z. Yang, F.-X. Xiao, H.B. Yang, B. Liu, Y. Yang, Carbon nanotube catalysts: recent advances in synthesis, characterization and applications. Chem. Soc. Rev. 44(10), 3295-3346 (2015). doi:10.1039/c4cs00492b

18. D.-W. Wang, D. Su, Heterogeneous nanocarbon materials for oxygen reduction reaction. Energy Environ. Sci. 7(2), 576-591 (2014). doi:10.1039/c3ee43463j

19. W.Y. Wong, W.R.W. Daud, A.B. Mohamad, A.A.H. Kadhum, K.S. Loh, E.H. Majlan, Recent progress in nitrogen-doped carbon and its composites as electrocatalysts for fuel cell applications. Int. J. Hydrogen Energy 38(22), 9370-9386 (2013). doi:10.1016/ j.ijhydene.2012.12.095

20. R. Chetty, S. Kundu, W. Xia, M. Bron, W. Schuhmann, V. Chirila, W. Brandl, T. Reinecke, M. Muhler, PtRu nanoparticles supported on nitrogen-doped multiwalled carbon nanotubes as catalyst for methanol electrooxidation. Electrochim. Acta 54(17), 4208-4215 (2009). doi:10.1016/j.electacta.2009.02.073

21. H. Jin, T. Xiong, Y. Li, X. Xu, M. Li, Y. Wang, Improved electrocatalytic activity for ethanol oxidation by Pd@N-doped carbon from biomass. Chem. Commun. 50(84), 12637-12640 (2014). doi:10.1039/c4cc06206j

22. C.E. Chan-Thaw, A. Villa, G.M. Veith, L. Prati, Identifying the role of N-heteroatom location in the activity of metal catalysts for alcohol oxidation. ChemCatChem 7(8), 1338-1346 (2015). doi:10.1002/cctc. 201402951

23. J. Chang, X. Sun, L. Feng, W. Xing, X. Qin, G. Shao, Effect of nitrogen-doped acetylene carbon black supported Pd nanocatalyst on formic acid electrooxidation. J. Power Sources 239, 94-102 (2013). doi:10.1016/j.jpowsour.2013.03.066

24. Y. Shao, J. Sui, G. Yin, Y. Gao, Nitrogen-doped carbon nanostructures and their composites as catalytic materials for proton exchange membrane fuel cell. Appl. Catal. B 79(1), 89-99 (2008). doi:10.1016/j.apcatb.2007.09.047

25. E. Antolini, Nitrogen-doped carbons by sustainable $\mathrm{N}$ - and C-containing natural resources as nonprecious catalysts and catalyst supports for low temperature fuel cells. Renew. Sust. Energy Rev. 58, 34-51 (2016). doi:10.1016/j.rser.2015.12.330

26. M. Sevilla, L. Yu, L. Zhao, C.O. Ania, M.-M. Titiricic, Surface modification of CNTs with N-Doped carbon: an effective way of enhancing their performance in supercapacitors. ACS Sustain. Chem. Eng. 2(4), 1049-1055 (2014). doi:10.1021/sc500069h

27. Q.-L. Zhang, J.-N. Zheng, T.-Q. Xu, A.-J. Wang, J. Wei, J.-R. Chen, J.-J. Feng, Simple one-pot preparation of Pd-on-Cu nanocrystals supported on reduced graphene oxide for enhanced ethanol electrooxidation. Electrochim. Acta 132, 551-560 (2014). doi:10.1016/j.electacta.2014.03.159

28. Z.X. Liang, T.S. Zhao, J.B. Xu, L.D. Zhu, Mechanism study of the ethanol oxidation reaction on palladium in alkaline media. Electrochim. Acta 54(8), 2203-2208 (2009). doi:10.1016/j.elec tacta.2008.10.034

29. J.-N. Zheng, L.-L. He, F.-Y. Chen, A.-J. Wang, M.-W. Xue, J.-J. Feng, A facile general strategy for synthesis of palladium-based bimetallic alloyed nanodendrites with enhanced electrocatalytic performance for methanol and ethylene glycol oxidation. J. Mater. Chem. A 2(32), 12899-12906 (2014). doi:10.1039/ C4TA01647E

30. F. Zhu, G. Ma, Z. Bai, R. Hang, B. Tang, Z. Zhang, X. Wang, High activity of carbon nanotubes supported binary and ternary Pd-based catalysts for methanol, ethanol and formic acid electrooxidation. J. Power Sources 242, 610-620 (2013). doi:10.1016/j. jpowsour.2013.05.145

31. W. Li, Y. Huang, D. Tang, T. Zhang, Y. Wang, A new composite support for Pd catalysts for ethylene glycol electrooxidation in alkaline solution: effect of $(\mathrm{Ru}, \mathrm{Sn}) \mathrm{O}_{2}$ solid solution. Electrochim. Acta 174, 178-184 (2015). doi:10.1016/j.electacta.2015. 05.166

32. H. Chen, Y. Huang, D. Tang, T. Zhang, Y. Wang, Ethanol oxidation on $\mathrm{Pd} / \mathrm{C}$ promoted with $\mathrm{CaSiO}_{3}$ in alkaline medium. Electrochim. Acta 158, 18-23 (2015). doi:10.1016/j.electacta. 2015.01.103

33. J. Zhao, M. Shao, D. Yan, S. Zhang, Z. Lu et al., A hierarchical heterostructure based on Pd nanoparticles/layered double hydroxide nanowalls for enhanced ethanol electrooxidation. J. Mater. Chem. A 1(19), 5840-5846 (2013). doi:10.1039/ c3ta10588a

34. P. Wu, Y. Huang, L. Kang, M. Wu, Y. Wang, Multisource synergistic electrocatalytic oxidation effect of strongly coupled PdM $(\mathrm{M}=\mathrm{Sn}, \mathrm{Pb}) / \mathrm{N}$-doped graphene nanocomposite on small organic molecules. Sci. Rep. 5, 14173 (2015). doi:10.1038/ srep 14173

35. G. Yang, Y. Chen, Y. Zhou, Y. Tang, T. Lu, Preparation of carbon supported Pd-P catalyst with high content of element phosphorus and its electrocatalytic performance for formic acid oxidation. Electrochem. Commun. 12(3), 492-495 (2010). doi:10.1016/j.elecom.2010.01.029

36. K.S. Kim, A.F. Gossmann, N. Winograd, X-ray photoelectron spectroscopic studies of palladium oxides and the palladiumoxygen electrode. Anal. Chem. 46(2), 197-200 (1974). doi:10. 1021/ac60338a037

37. R. Arrigo, M.E. Schuster, Z. Xie, Y. Yi, G. Wowsnick et al., Nature of the N-Pd interaction in nitrogen-doped carbon nanotube catalysts. ACS Catal. 5(5), 2740-2753 (2015). doi:10.1021/acs catal.5b00094

38. L. Chen, X. Cui, Y. Wang, M. Wang, F. Cui et al., One-step hydrothermal synthesis of nitrogen-doped carbon nanotubes as an efficient electrocatalyst for oxygen reduction reactions. Chem. Asian J. 9(10), 2915-2920 (2014). doi:10.1002/asia.201402334

39. X. Chen, G. Wu, J. Chen, X. Chen, Z. Xie, X. Wang, Synthesis of "clean" and well-dispersive pd nanoparticles with excellent electrocatalytic property on graphene oxide. J. Am. Chem. Soc. 133(11), 3693-3695 (2011). doi:10.1021/ja110313d 